for every person without an advance directive to have mandatory medical treatment. Decide now or pay later. The intention behind this suggestion to make treatment obligatory and "force consensus by legislation" is primarily to spur to action those who have strong views but fail to document them. It is indicative of the book's underlying premise that unwanted medical treatment is likely to be the penalty for those whose choice is not to choose at all.

In this respect, perhaps, Making Sense of Advance Directives occasionally makes less than good sense. It presents a vision of advance directives as the way forward despite the fact that they are under-used, currently less popular in America than health care proxies and replete with problems which the author conscientiously documents. The current edition updates but also repeats the same points as the original 1991 version, the concluding chapter of which optimistically forecast an important future for advance directives, which "ultimately demonstrate the true nature of autonomy". The final chapter of the current edition begins in identical vein, reiterating the same emphasis on their popularity and significance. However, the reader may feel this is unsupported by any new evidence.

Intended for clinicians and patients, the book provides considerable detail and discussion about the use and limitations of living wills in the United States. There is something for everyone interested in the American endof-life debate, from a brief history of the concept of "informed consent" to model forms for the drafting of advance directives and conferring power of attorney. Much of the commentary and advice makes sound good sense. Patients are told they have "obligations to make their advance directives good guidance for others" or risk not getting what they want. Doctors are informed that advance directives "are not marching orders but documents of engagement". The significance of this military metaphor, however, resonates throughout as a sense of confrontation rather than cooperation permeates the text. The author herself is a proponent of advance directives, portraying them as an imperfect but potentially vital bulwark against doctors' determination to treat despite the odds. Her approach, while not continuously or virulently anti-medical, stresses that patients need to have advance decisions documented, witnessed and notarised if they wish to avoid doctors deciding for them. Formality and legality are of the essence, displacing notions of trust. While regrettable, this may well be a faithful reflection of American delivery of health care.

The underlying message is that doctors are unreliable in assessing patients' interests or making substituted judgments. Judges are often no better. True enough in general perhaps, although the author occasionally exaggerates the facts. "The earliest medical applications of substituted judgment" she explains "explicitly pitted medical against psychosocial views of the patient's best interests, giving court approval for subjecting mentally retarded patients to the medical demands of major surgery to donate kidneys to siblings of normal intellect". Visions are thereby conjured of cohorts of the mentally incapacitated going under the knife to satisfy "medical demands". The one case cited in which this actually occurred, however, has been a focus of debate for almost thirty years, precisely because of its exceptional and controversial nature. In the absence of other evidence, it should not be taken as indicative of a trend.

Additions to the earlier edition consist of references to the Cruzan case and the Patient Self Determination Act and a brief discussion of futility. The endnotes accompanying the text are also extensively and usefully expanded. As before, American case law since Quinlan is discussed and a state by state catalogue of relevant statute appended. No reference, however, is made to developments in other jurisdictions, although these have been closely imitative of US case law and reinforce some arguments the author supports. Disappointingly superficial is the handling of the complex debates about the continuity of personal identity and the financial and potentially pejorative implications of governments which promote treatment refusal. Both are raised in a perfunctory way although some additional references are cited for readers wishing to go further. Like its predecessor, the book is essentially practical and informative rather than philosophical or speculative.

The author's style is clear and accessible but occasionally irritating, varying from the portentous to the frivolous; from discussion of Aristotle, honour and nobility to the "rich Johnny-come-lately bumping others off the transplant list". Written for an American audience, the approach and compressed phraseology may seem alien to other readers. People becomer. "decisionally incapacitated" and" death is "a socially disfavoure $\overrightarrow{\text {. }}$ choice". There is some repetition and overlap between many of the chapters which, while useful for the reade는 wishing to dip into the book, can give the impression of over-emphasis or the usual, well-established arguments్ which recur throughout.

Consistency in medical decision $\overrightarrow{0}$ making is clearly desirable but at$\vec{L}$ times the author seems to over-value్ uniformity and standardisation in के way incompatible with the vagaries messiness and unavoidable uncertain iv ties of real life. The quest for a $\operatorname{stan}_{\tilde{\omega}}^{\omega}$ dard set of rules applicable to any case. without an advance statement convey\& a paralysing sense that no valid decio sion can ethically be made withou? awareness of the individual's formee wishes. Abuses, mistakes and dis agreements do occur when the patient's views are unknown (and not $\overrightarrow{0}$ all are avoidable by a living will). Buf treatment decisions are made, using as a criterion what seems humane an reasonable in the particular circums stances, without defying societal oํㅡ professional standards. While encour aging respect for the views of thos who are articulate about the kind of death they want, it must also be pos옥 sible to respect others who cannof bear to think about it or who mat simply be willing to trust health pro fessionals to get it right. The book is్ clearly intended for those with and interest in exploring methods of extending choice within a sometimes unsupportive environment.

ANN SOMMERVILLE $B M A$, Dept of Medical Ethics The Rules of Insanity:
Moral Responsibility
and the Mentally IIl
Offender Carl Elliott, Albany, State University of New York Press, 1996, x and $143 \stackrel{\mathscr{S}}{+}$ pages, $\$ 17.95$ sc, $\$ 54.95$ hc.

The aim of this book is "to give som answers to questions about the condi tions under which mentally dis气 ordered people should be held morall responsible for their actions". The answers turn out to be complex Indeed, as Carl Elliott stresses, the. title of his book is in part iron because " $[\mathrm{m}]$ orally speaking, there are 
no rules of insanity". The book, in other words, does not offer a general theory or responsibility in terms of which we can judge how far individuals may or may not be exonerated from responsibility in certain circumstances. Rather, the philosophical approach is like that of Wittgenstein in the sense that the stress is on particularities rather than generalities. "There is little that one can usefully say about the responsibility of mentally ill persons as a class." On the other hand Elliott does attempt a taxonomy of mental disorders and relates moral responsibility to these types of mental disorder and to the specific circumstances of individual cases. The moral taxonomy of mental disorders is derived from the (broadly Aristotelian) conceptual framework. Aristotle recognised two types of excuses - ignorance and compulsion. Derivatively, Elliott argues that insanity pleas have generally focused on two sorts of tests - cognitive and volitional. In other words, some disorders, such as schizophrenia, affect a person's beliefs or other cognitive abilities, and depressions, and others, such as kleptomania and some psychosexual disorders, affect desires. This leaves the "trouble spots" of personality disorders and, notoriously, the psychopath, who fall outside the usual categories. These categories merit and receive detailed discussion.

Elliott stresses that he is concerned with moral as distinct from legal responsibility. Nevertheless, the book does discuss various legal rules, rulings and cases, thus relating moral and legal responsibility. This is helpful for those, psychiatrists, lawyers and public-policy makers, who must take the actual decisions which philosophers discuss. The book is a model of applied philosophy in the best sense. It is philosophy in the best sense first in that the arguments used show an awareness of the central thinking on responsibility from Aristotle through to John Mackie's “straight rule of responsibility", and secondly in that the analysis of responsibility is linked to some of the main themes of philosophy, such as the relationship between action and the self or the nature of personal identity. It is "applied" in that it shows detailed knowledge of the first-order psychiatric and legal literature (as he says "the devil is in the detail") and also recommends ways of seeing this, often confusing, literature. No doubt the fact that Elliott is qualified in medicine as well as philosophy has enabled him to penetrate the dense jungle of writing on this topic, but what he emerges with is a clear, and clearly written, guide which can be strongly recommended.

R S DOWNIE

Department of Philosophy, Glasgow University

\section{The Patient in the Family: an Ethics of Medicine and Families}

\author{
H L Nelson and J L Nelson, New \\ York and London, Routledge, 1995, \\ $£ 37.50$ hc, $£ 11.99$ sc.
}

When discussing with medical students the role of families in treatment decisions for incompetent patients, the students' main concern is that families might have nasty motives. But when I ask students to imagine that someone close to them is ill, and incompetent, they feel that they are in a better position to know what is best for their relative than are the professionals.

Hilde and James Nelson have written a stimulating and important book which seeks to redress the neglect which families have received in modern discussions of bioethics. They start from the assertion that the two most important institutions which provide care for sick people are medicine, and the family. "Increasingly" they write, "these two systems of care are rubbing each other the wrong way" (page ix).

Nelson and Nelson take issue with the extreme individualism of much of modern bioethics. The ethics of autonomy have evolved in the context of political philosophy as a means of protecting the individual from unwarranted outside interference. In the context of modern medical ethics respect for autonomy can emphasise the need for the individual to be protected against interference from the family. Hence the view of the family which medical students so readily adopt. But for most people most of the time families are a support, and this is particularly the case when one of their members is sick.

Nelson and Nelson use this simple insight to develop a bioethics which is refreshingly distinct from the common emphasis on autonomy. But they go further than this. They argue that the importance of families, in the medical context, is not simply that they are providers of care. This would be to see families as of only instrumental value in relation to the sick patient. They write: "the fact that family members can make decisions for us when we are very ill is really beside the point; we want them there not for what they can do for us but because they love us" (page 52). They develop their arguments through what they call "stars to steer by". They write: "But if all the things we value can't be seen as instances of some one master value or neatly ranked in one Great Chain of Being, then moral life becomes much less a matter of calculation and more a matter of navigation, of trying to steer a prudent course among independent and sometimes incompatible values" (page 73). There are seven of these stars:

1. Family members aren't replaceable by similar (or better) qualified people; 2. Family members are stuck with each other;

3. The need for intimacy produces responsibilities;

4. Causing someone to exist produces responsibilities;

5. Virtues are learned at our mothers' (and fathers') knees;

6. Families are ongoing stories;

7. In families, motives matter a lot.

Nelson and Nelson explain the use of the seven stars through extensive examples from both non-medical and medical settings. For example, at one point they discuss whether parents should try and find care givers "wiser and richer than they, to give their child the best possible upbringing". They dismiss this obligation saying that: "the point is not that our children get the best possible upbringing, but that they get the good of being brought up by $u s$ " (their italics). They then go on to consider proxy decisionmaking. They argue that I might, for example, want my wife to act as my proxy not simply because she is the person most likely to make the decision which is in my best interests but simply because I want the decision to be made by her. Nelson and Nelson see this as an example of the first "star": "family members aren't replaceable by similar (or better) qualified people".

This book has considerable range. In addition to discussions of consent and decision-making, it covers in some detail our responsibilities to the elderly, assisted reproduction, and distributive justice. The strength of 